\title{
Physical activity intensity and surrogate markers for cardiovascular health in adolescents
}

\author{
Thomas Radtke $\cdot$ Susi Kriemler • Prisca Eser • \\ Hugo Saner • Matthias Wilhelm
}

Received: 22 June 2012/ Accepted: 31 October 2012/Published online: 16 November 2012

(C) Springer-Verlag Berlin Heidelberg 2012

\begin{abstract}
We examined the impact of physical activity (PA) on surrogate markers of cardiovascular health in adolescents. 52 healthy students (28 females, mean age $14.5 \pm 0.7$ years) were investigated. Microvascular endothelial function was assessed by peripheral arterial tonometry to determine reactive hyperemic index (RHI). Vagal activity was measured using $24 \mathrm{~h}$ analysis of heart rate variability [root mean square of successive normal-tonormal intervals (rMSSD)]. Exercise testing was performed to determine peak oxygen uptake $\left(\dot{V} \mathrm{O}_{2 \text { peak }}\right)$ and maximum power output. PA was assessed by accelerometry. Linear regression models were performed and adjusted for age, sex, skinfolds, and pubertal status. The cohort was dichotomized into two equally sized activity groups (low vs. high) based on the daily time spent in moderate-tovigorous PA (MVPA, 3,000-5,200 counts $\mathrm{min}^{-1}$, model 1) and vigorous PA (VPA, $>5,200$ counts $\mathrm{min}^{-1}$, model 2 ). MVPA was an independent predictor for $\operatorname{rMSSD}(\beta=$ $0.448, P=0.010)$, and VPA was associated with maximum power output $(\beta=0.248, P=0.016)$. In model 1 , the high MVPA group exhibited a higher vagal tone (rMSSD $49.2 \pm 13.6$ vs. $38.1 \pm 11.7 \mathrm{~ms}, P=0.006)$ and a lower systolic blood pressure $(107.3 \pm 9.9$ vs.
\end{abstract}

Communicated by Keith Phillip George.

T. Radtke $(\bowtie) \cdot$ P. Eser $\cdot$ H. Saner $\cdot$ M. Wilhelm Division of Cardiovascular Prevention, Rehabilitation and Sports Cardiology, University Clinic for Cardiology, Inselspital, University Hospital and University of Bern,

3010 Bern, Switzerland

e-mail: thomas.radtke@insel.ch

S. Kriemler

Swiss Tropical and Public Health Institute, University of Basel, Basel, Switzerland
$112.9 \pm 8.1 \mathrm{mmHg}, P=0.046)$. In model 2 , the high VPA group had higher maximum power output values $\left(3.9 \pm 0.5\right.$ vs. $\left.3.4 \pm 0.5 \mathrm{~W} \mathrm{~kg}^{-1}, P=0.012\right)$. In both models, no significant differences were observed for RHI and $\dot{V} \mathrm{O}_{2 \text { peak. }}$. In conclusion, in healthy adolescents, PA was associated with beneficial intensity-dependent effects on vagal tone, systolic blood pressure, and exercise capacity, but not on microvascular endothelial function.

Keywords Peripheral arterial tonometry $\cdot$ Heart rate variability $\cdot$ Blood pressure $\cdot$ Fitness $\cdot$ Accelerometry

\section{Introduction}

Risk factors for cardiovascular disease (CVD) develop early in life (Berenson et al. 1998) and tend to cluster in adulthood. Physical activity (PA) plays a pivotal role in the prevention of CVD and is inversely related with clustering of CVD risk factors in children and adolescents (Andersen et al. 2006). In adults, reduced exercise capacity, endothelial dysfunction and diminished autonomic nervous system activity are predictive for future cardiovascular events and/or mortality (Myers et al. 2002; Rubinshtein et al. 2011; Tsuji et al. 1994; Zulfiqar et al. 2010).

Alterations in cardiovascular health-related markers are already present in healthy but inactive children and adolescents when compared to their active peers (Hopkins et al. 2009; Nagai and Moritani 2004; Trigona et al. 2010). Regular PA favorably affects the cardiovascular system and improves cardiorespiratory fitness (Anderssen et al. 2007), endothelial function (Clarkson et al. 1999), and autonomic tone (Gutin et al. 2005; Nagai et al. 2004). In this context, data on the nitric oxide-mediated vascular endothelial function of the large arteries indicate positive 
associations with either habitual general PA (Abbott et al. 2002; Pahkala et al. 2011) or predominantly high intensity PA (Hopkins et al. 2009, 2011). Stone et al. (2009) investigated the relationships between PA and resting microvascular function using iontophoresis combined with laser Doppler perfusion imaging in pre-pubertal boys. No association between PA levels and resting microvascular endothelial function was observed. However, their study included only healthy boys and since PA levels are known to decline from childhood to adolescence, with girls being consistently less active than boys (Nader et al. 2008), we considered it appropriate to assess the potentially beneficial effects of PA on microvascular endothelial function in a more heterogeneous group of mixed sex adolescents. Furthermore, the importance of PA intensity on most cardiovascular health related markers is less well understood.

Therefore, we simultaneously evaluated the impact of different levels of PA intensity on exercise capacity, microvascular endothelial function, and autonomic tone. We hypothesized that in healthy adolescents, greater volumes of at least moderate PA would be positively associated with enhanced microvascular endothelial function, cardiorespiratory fitness and autonomic tone.

\section{Materials and methods}

\section{Participants}

A convenient sample of healthy adolescents of normal body weight was recruited from an elementary school in Olten, Switzerland. Exclusion criteria were diseases or behaviors that potentially affect microvascular endothelial function at an early age such as juvenile rheumatoid arthritis or vascular diseases (Reynaud's or Kawasaki's disease), hypertension (National High Blood Pressure Education Program Working Group on High Blood Pressure in Children and Adolescents 2004), obesity (Fernandez et al. 2004), diabetes, depression, smoking, and intake of vasoactive medications. Written informed consent was obtained from all participating subjects and parents/caregivers. Ethical approval was obtained from the cantonal ethical committee of Bern, Switzerland.

\section{Experimental design}

Consenting adolescents reported to the temporary laboratory set up at the school on one occasion to complete a number of physiological examinations. The tests were divided into two 1-h sessions. In the first session anthropometry, vital signs and microvascular endothelial function were measured after an overnight fast. Then, subjects had a 1-h break and all of them received a standardized snack containing a chocolate milk drink and a granola bar before they performed a maximal cardiopulmonary exercise test in the second test session. Ambulatory 24-h electrocardiography was recorded on the same day and objective measures of PA using accelerometry were obtained within \pm 7 days after the examination. All subjects completed the same testing schedule between 8:00 and 11:00 a.m. to avoid any influence of circadian pattern.

Anthropometric and hemodynamic measurements and family history

All anthropometric measures were taken by trained staff according to standard procedures. Body mass was measured with light clothing to the nearest $0.1 \mathrm{~kg}$ using a digital-balanced scale and stature to the nearest $0.5 \mathrm{~cm}$ using a wall-mounted stadiometer. Body mass index (BMI) was calculated as body mass divided by stature squared $\left(\mathrm{kg} \mathrm{m}^{-2}\right)$. Waist circumference was measured twice at the midpoint between the lowest rib and the iliac crest using an anthropometric tape. Skinfold thickness was measured in triplicate on the right side of the body and to the nearest $0.2 \mathrm{~mm}$ with a Harpenden caliper. The sum of four sites (triceps, biceps, subscapular and suprailicial) was calculated and the average of three measurements was used for analysis. Pubertal stage (Tanner 1-5) was assessed using a validated self-assessment tool (Morris 1980). Girls were asked about their current menstrual cycle phase at the time of testing. Menstrual cycles were divided into follicular phase (day 1-14 of the menstrual cycle) and luteal phase (day 15-28 of the menstrual cycle). Resting blood pressure was measured three times at 2-min interval at the right arm with an adequate sized cuff using an oscillometric device (Dinamap XL; Criticon Inc., Tampa, FL, USA). The $z$ transformed mean of the three measurements based on age- and sex-specific norms (National High Blood Pressure Education Program Working Group on High Blood Pressure in Children and Adolescents 2004) were used for analyses. A 12-lead resting electrocardiograph (ECG) was performed to exclude those with increased risk for exercise-induced arrhythmias such as long QT-syndrome. We assessed familial CVD risk factors using a self-administered questionnaire for both parents/ caregivers. The questionnaire covered the most relevant risk factors for CVD, i.e. hypertension, diabetes, dyslipidemia, smoking and premature cardiovascular death. Premature cardiovascular mortality was defined as sudden death or myocardial infarction occurring $<55$ years of age in men and $<65$ years of age in women.

Assessment of microvascular endothelial function

Microvascular endothelial function was measured by peripheral arterial tonometry (Endo-PAT2000 ${ }^{\circledR}$, Itamar 
Medical Ltd., Israel) in a quiet, temperature controlled and light dimmed room $\left(22-24^{\circ} \mathrm{C}\right)$. Reproducibility and feasibility of this device have recently been demonstrated in healthy adolescents (Selamet Tierney et al. 2009). Testing was performed after an overnight fast with subjects in supine position with the hands at heart level and the fingers hanging freely. Prior to testing, subjects rested for at least $5 \mathrm{~min}$ to achieve steady-state conditions. Pneumatic fingertip probes were placed on both index fingers and pulsevolume amplitudes were recorded. After a 5-min baseline measurement, ischemia was induced by a cuff that was inflated to at least $220 \mathrm{mmHg}$ over the non-dominant upper arm and maintained for $5 \mathrm{~min}$. The cuff was then rapidly deflated and bilateral pulse-volume amplitudes were recorded for $5 \mathrm{~min}$. The RHI was automatically calculated by a computerized algorithm of the software program.

\section{Assessment of PA}

PA measurements were obtained using a uniaxial accelerometer (MTI/CSA 7164, ActiGraph, Shalimar, FL, USA). The monitor was attached at the right hip with a belt and worn for eight consecutive days, except for water activities, contact sports and sleeping. Data from the accelerometers were downloaded and checked for spurious counts. The accelerometer was programmed to record PA data (raw activity counts and steps) every $5 \mathrm{~s}$ which were summed for each $60 \mathrm{~s}$ for further analyses. Excessively high counts $(\geq 20,000)$ were removed from the analysis (Masse et al. 2005). Sustained periods of $\geq 20 \mathrm{~min}$ of continuous zero values were interpreted as being due to unworn accelerometers and were removed. A minimum of 5 days including one weekend day with $\geq 9 \mathrm{~h}$ of wearing time on each day were required for inclusion in the data analysis. Data are expressed based on validated cut-offs (Treuth et al. 2004), as total daily PA (counts $\min ^{-1}$ ), light PA (100-2,999 counts $\min ^{-1}$ ), MVPA (3,000-5,200 counts $\left.\min ^{-1}\right)$ and VPA $\left(>5,200\right.$ counts $\left.\min ^{-1}\right)$. Daily sedentary activity was evaluated using a threshold of $\leq 100$ counts $\min ^{-1}$ (Hopkins et al. 2012; Treuth et al. 2004). In order of a 5-min bout to classify for MVPA or VPA, at least $4 \mathrm{~min}$ had to meet or exceed the respective threshold. Bouts of PA are expressed as the total number of daily bouts and the average duration per bout (min). Activity data were analyzed between 07:00 a.m. and 11:00 p.m.

Assessment of cardiorespiratory fitness

Cardiopulmonary exercise testing was performed on an electromagnetically braked cycle ergometer (Schiller 911 S, Schiller-Reomed AG, Dietikon, Switzerland) with online gas analysis until exhaustion. A progressive incremental cycle protocol with an initial load of $20 \mathrm{~W}$ and an increase of 10 to $25 \mathrm{~W}$ each min was chosen to assure subjects achieve their limit of tolerance within $10 \pm 2 \mathrm{~min}$. Respiratory parameters were measured continuously in an open circuit system (CS 200, Schiller-Reomed AG, Dietikon, Switzerland). Heart rate and cardiac rhythm were continuously analyzed using a 12-lead ECG. All subjects received verbal encouragement to reach their maximal performance. Clinical signs of exhaustion and further objective criteria that were used to confirm peak oxygen uptake $\left(\dot{V} \mathrm{O}_{2 \text { peak }}\right)$ had been achieved: heart rate $>90 \%$ of predicted maximum heart rate for age, or respiratory exchange ratio $>1.10$, or oxygen plateau $<2 \mathrm{~mL} \mathrm{~kg}^{-1} \min ^{-1}$ increase in $\dot{V} \mathrm{O}_{2}$ with increasing work rate. The highest $\dot{V} \mathrm{O}_{2}$ averaged over $15 \mathrm{~s}$ during the test was taken as $\dot{V} \mathrm{O}_{2 \text { peak }}$.

Analysis of autonomic tone by heart rate variability (HRV)

Ambulatory electrocardiography (AECG) was performed for $24 \mathrm{~h}$ and time domain parameters of HRV were analyzed according to current recommendations (Task Force 1996). The monitor (Lifecard CF, Del Mar Reynolds Medical Inc, Irvine, CA, USA) provides ECG data with high accuracy (12-bit resolution) and a sampling frequency of $1,024 \mathrm{~Hz}$. The device and electrodes were attached to the chest on a normal school day between 10:00 and 12:00 a.m. All ECG recordings were beat-by-beat analyzed and interpreted using the Pathfinder Software (Spacelabs Healthcare, Nuremberg, Germany) and manually re-evaluated by an experienced cardiologist (M.W.). Premature atrial and ventricular contractions were classified according to onset and QRS morphology. For HRV analysis, the program eliminated $1 \mathrm{RR}$ interval before, and 2 intervals after each non-sinus beat. Four standard 24-h time domain measures were calculated: the standard deviation of normal-to-normal intervals (SDNN), the HRV triangular index, the standard deviation of the average normal-tonormal interval (SDANN), and the square root of the mean squared differences of successive normal-to-normal intervals (rMSSD). In addition to the time domain analyses, measures of the maximum, minimum and mean heart rate over the 24-h recording were recorded.

Statistical analysis

Statistical analysis was performed using the STATA 11 statistical software package (STATA Corporation, College Station, TX, USA). Distribution of the data was examined using the Shapiro-Wilk test. Data are presented as mean \pm standard deviation or median (inter-quartile range), depending on whether the data were normally distributed or not. Anthropometric characteristics were 
analyzed using the Student's $t$ test or Mann-Whitney $U$ test, as indicated. The $\chi^{2}$ test was used to compare baseline categorical variables between the groups. Multiple linear regression analysis was performed to assess the influence of factors (MVPA, VPA, age, sex, skinfold and pubertal status) on the prespecified outcome variables (RHI, rMSSD, $\dot{V} \mathrm{O}_{2 \text { peak }}$ and maximum power output). We then applied two different regression models with the cohort dichotomized into two equally sized activity groups (low vs. high) based either on the daily time spent in MVPA (3,000-5,200 counts $\min ^{-1}$, model 1) or VPA $\left(>5,200\right.$ counts $\min ^{-1}$, model 2$)$. Differences in the outcome variables within the dichotomized groups were further analysed using linear regression modelling. A $P$ value $<0.05$ was considered to indicate statistical significance.

\section{Results}

Figure 1 presents a flow chart of study recruitment and inclusion. Of the 52 adolescents (28 females, mean age $14.5 \pm 0.7$ years), PA data of 7 boys did not meet the inclusion criteria and these subjects were therefore excluded from the analysis, leaving 45 adolescents in analyzed sample. The ActiGraph accelerometer was worn for a mean of $7.46 \pm 0.78$ days. Baseline characteristics revealed taller stature, higher $\dot{V} \mathrm{O}_{2 \text { peak }}$ and lower skinfolds for boys than girls. There were no significant differences in age, pubertal status and familial CVD risk factors between boys and girls (Table 1). Total PA for the study sample was 387.6 (118.5) counts $\min ^{-1}$. The median daily time (interquartile range) spent in sedentary activity, light PA, MVPA and VPA for the study sample was 721.7 (82.5), 145.1 (45.9), 34.0 (14.4) and 9.5 (8.0) $\mathrm{min} \mathrm{day}^{-1}$, respectively. Only $16 \%$ of the whole study population achieved the recommendations of $60 \mathrm{~min}^{-1 a y}{ }^{-1}$ of MVPA. No differences were observed in PA levels between boys and girls. Fifty-nine percent of subjects classified as low MVPA were also classified as low VPA and $61 \%$ of subjects classified as high MVPA were also classified as high VPA.

Impact of PA on surrogate markers of cardiovascular health

In multiple linear regression analysis, MVPA was significantly associated with vagal activity. VPA, sex and sum of four skinfolds were independent predictors for maximum power output. No significant associations were found

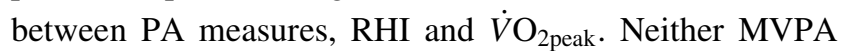
nor VPA was a significant predictor for $\dot{V} \mathrm{O}_{2 \text { peak }}$ (Table 2).

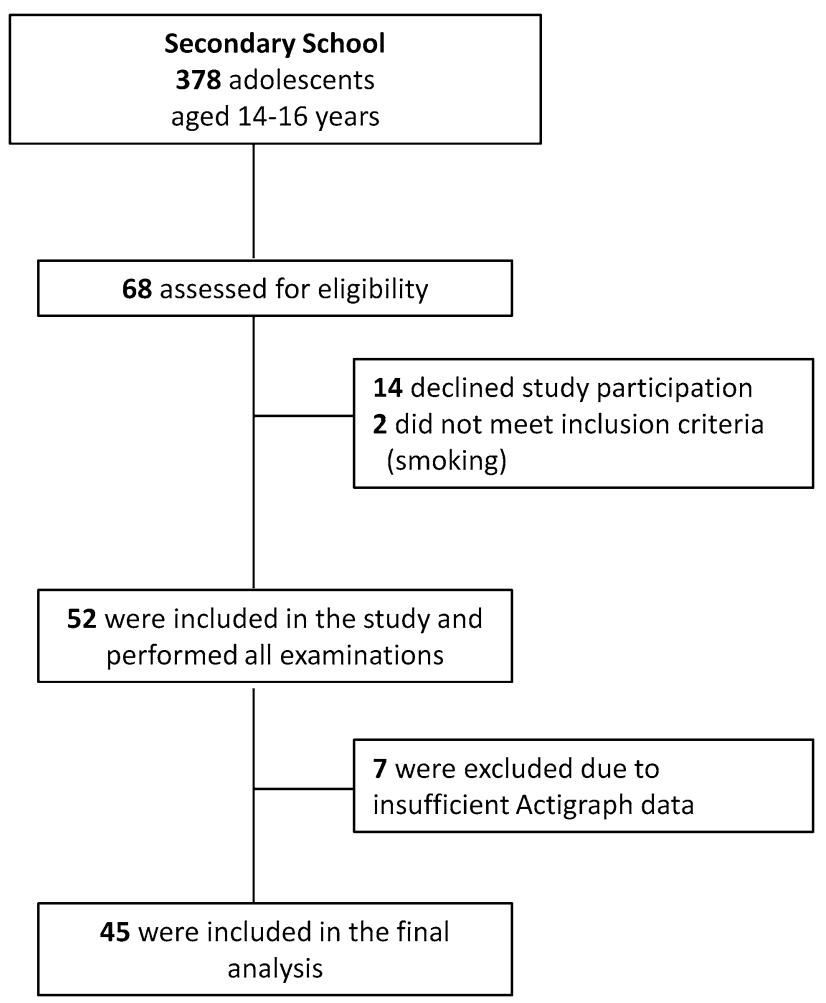

Fig. 1 Flow chart of subject recruitment and study enrolment

Dichotomization according to MVPA (model 1) and VPA (model 2)

In both models, dichotomized PA groups did not differ with regard to sex, pubertal status and girls' menstrual cycle phases. In model 1 , there was a trend of higher volumes in total PA (counts $\min ^{-1}$ ) and VPA (min day ${ }^{-1}$ ). No differences were observed for light PA and sedentary activity. Compared to the low MVPA group, the high MVPA group performed significantly more $\geq 5$ min bouts of MVPA. The VPA groups (model 2) differed in the amount of total PA, MVPA, VPA, and in the number and average time per bout of vigorous intensity (Table 3 ).

Microvascular endothelial function (reactive hyperemic index)

In both models, the RHI showed no significant differences between the low and high PA group (Fig. 2).

Autonomic tone (heart rate variability)

In model 1, the high MVPA group exhibited a higher overall sympathetic nervous system activity (SDNN, $P=0.019)$, enhanced vagal activity (rMSSD; $P=0.006$ ) and a lower minimum heart rate $(P=0.009)$, compared to the low MVPA group (Table 4). Regression analysis 
Table 1 Baseline characteristics of the study population

\begin{tabular}{|c|c|c|c|c|}
\hline & All $(N=52)$ & Girls $(N=28)$ & Boys $(N=24)$ & $P$ value \\
\hline Age (years) & $14.5 \pm 0.7$ & $14.5 \pm 0.7$ & $14.5 \pm 0.7$ & 0.862 \\
\hline Stature $(\mathrm{m})$ & $1.69 \pm 0.1$ & $1.66 \pm 0.5$ & $1.73 \pm 0.1$ & $<0.001$ \\
\hline Body mass $(\mathrm{kg})$ & $57.7(10.3)$ & $55.6(9.4)$ & $60.4(11.7)$ & 0.144 \\
\hline Body mass index $\left(\mathrm{kg} \mathrm{m}^{-2}\right)$ & $19.8 \pm 2.4$ & $20.3 \pm 2.6$ & $19.8 \pm 2.5$ & 0.506 \\
\hline Waist circumference $(\mathrm{cm})$ & $69.5(8.1)$ & $67.5(7.5)$ & $71.4(6.4)$ & 0.114 \\
\hline Sum of four skinfolds $(\mathrm{mm})$ & $39.7(23.4)$ & $48.0(13.8)$ & $33.5(16.1)$ & $<0.001$ \\
\hline Resting heart rate (bpm) & $69.4 \pm 10.6$ & $71.0 \pm 10.9$ & $67.5 \pm 10.1$ & 0.238 \\
\hline Systolic blood pressure (mmHg) & $110.0 \pm 9.4$ & $109.2 \pm 7.0$ & $111.4 \pm 12.5$ & 0.466 \\
\hline$\dot{V} \mathrm{O}_{2 \text { peak }}\left(\mathrm{mL} \mathrm{kg}^{-1} \min ^{-1}\right)$ & $44.8 \pm 10.1$ & $39.9 \pm 8.1$ & $51.6 \pm 7.5$ & $<0.001$ \\
\hline Power output ( $\mathrm{W} \mathrm{kg}^{-1}$ ) & $3.8 \pm 0.7$ & $3.3 \pm 0.4$ & $4.2 \pm 0.5$ & $<0.001$ \\
\hline Peak heart rate (bpm) & $191.9 \pm 7.4$ & $190.5 \pm 7.9$ & $193.4 \pm 6.9$ & 0.167 \\
\hline Accelerometer wear time (days) & $8.0(1.0)$ & $8.0(1.0)$ & $7.0(1.0)$ & 0.193 \\
\hline $\operatorname{MVPA}\left(\min \mathrm{day}^{-1}\right)$ & $33.5 \pm 11.2$ & $31.9 \pm 10.0$ & $36.2 \pm 11.8$ & 0.261 \\
\hline \multicolumn{5}{|l|}{ Tanner stage } \\
\hline 2 & $1(0.2 \%)$ & - & $1(0.4 \%)$ & 0.585 \\
\hline 3 & $9(18 \%)$ & $6(21 \%)$ & $3(13 \%)$ & \\
\hline 4 & $33(63 \%)$ & $16(57 \%)$ & $16(67 \%)$ & \\
\hline 5 & $9(18 \%)$ & $5(18 \%)$ & $4(17 \%)$ & \\
\hline \multicolumn{5}{|l|}{ Familial CVD risk factors } \\
\hline Hypertension & $7(15 \%)$ & $4(15 \%)$ & $3(15 \%)$ & 0.971 \\
\hline Diabetes & $2(0.4 \%)$ & $1(4 \%)$ & $1(5 \%)$ & 0.849 \\
\hline Dyslipidemia & $9(20 \%)$ & $4(15 \%)$ & $5(25 \%)$ & 0.948 \\
\hline Smoking & $6(13 \%)$ & $3(12 \%)$ & $5(25 \%)$ & 0.482 \\
\hline Premature cardiovascular death & $4(9 \%)$ & $3(12 \%)$ & $3(15 \%)$ & 0.512 \\
\hline
\end{tabular}

Data are presented as mean $\pm \mathrm{SD}$ or median (inter-quartile range) or $N(\%)$. A $P$ value $<0.05$ indicates statistical significance bpm beats per minute, $C V D$ cardiovascular disease, $M V P A$ moderate-to-vigorous physical activity

performed in model 2 resulted in no significant differences between the low versus high VPA group in any HRVrelated parameters (Fig. 2).

Cardiorespiratory fitness

In model 1, no differences were observed in maximum power output and $\dot{V} \mathrm{O}_{2 \text { peak }}(42.4 \pm 10.2$ vs. $45.7 \pm 9.8$ $\mathrm{mL} \mathrm{kg}{ }^{-1} \min ^{-1}$ ) between the low versus high MVPA group. In comparison, in model 2 , the high VPA group had significantly higher maximum power output values $(P=$ $0.012)$, but no differences existed for $\dot{V} \mathrm{O}_{2 \text { peak }}(46.5 \pm 10.4$ vs. $41.6 \pm 9.3 \mathrm{~mL} \mathrm{~kg}^{-1} \mathrm{~min}^{-1}$, see Fig. 2).

\section{Blood pressure}

Lower systolic blood pressure values were observed in the high MVPA compared to the low MVPA group, whether expressed in absolute values (Fig. 2) nor age- and sex-adjusted $z$ scores $(0.065 \pm 0.77$ vs. $-0.531 \pm 0.84, P=0.017)$. No significant differences in systolic blood pressure were found between the VPA groups (model 2, Fig. 2).

\section{Discussion}

The key finding of our study was the intensity-dependent effect of PA on surrogate markers of cardiovascular health. In particular, high volumes of MVPA favorably affected vagal activity and systolic blood pressure, whereas high volumes of VPA contributed to an improvement in exercise capacity. However, in healthy adolescents, neither MVPA nor VPA was associated with microvascular endothelial function.

The lack of association between PA and microvascular endothelial function as measured by peripheral arterial tonometry (PAT) has not been described previously in this age group using accelerometry-derived PA data. Some issues related to the present findings need to be addressed. First, several studies using the flow-mediated dilation (FMD) technique to assess endothelial function of the brachial artery observed positive associations with PA in healthy children and adolescents (Abbott et al. 2002; Hopkins et al. 2009, 2011; Pahkala et al. 2011). Both PAT as a measure of microvascular endothelial function and the FMD technique that represents macrovascular function are to a large extent nitric oxide dependent (Nohria et al. 2006). 
Table 2 Impact of physical activity on surrogate markers of cardiovascular health

\begin{tabular}{|c|c|c|c|c|}
\hline & Beta coefficient & Standard error beta & Standardized $\beta$ & $P$ value \\
\hline \multicolumn{5}{|c|}{ Reactive hyperemic index $\left(R^{2}=0.083\right)$} \\
\hline MVPA & -0.007 & 0.007 & -0.199 & 0.296 \\
\hline VPA & -0.004 & 0.009 & -0.078 & 0.669 \\
\hline \multicolumn{5}{|l|}{$\mathrm{rMSSD}\left(\mathrm{ms} ; R^{2}=0.313\right)$} \\
\hline MVPA & 0.553 & 0.203 & 0.448 & 0.010 \\
\hline VPA & 0.018 & 0.259 & 0.011 & 0.946 \\
\hline Sex & -9.422 & 4.306 & -0.335 & 0.035 \\
\hline \multicolumn{5}{|c|}{ Power output ( $\left.\mathrm{W} \mathrm{kg}^{-1} ; R^{2}=0.731\right)$} \\
\hline Sex & -0.525 & 0.120 & -0.410 & $<0.001$ \\
\hline Sum of four skinfolds & -0.022 & 0.004 & -0.560 & $<0.001$ \\
\hline MVPA & 0.001 & 0.006 & 0.011 & 0.914 \\
\hline VPA & 0.018 & 0.007 & 0.248 & 0.016 \\
\hline \multicolumn{5}{|c|}{ Peak oxygen uptake $\left(\mathrm{mL} \mathrm{kg}^{-1} \min ^{-1} ; R^{2}=0.749\right)$} \\
\hline Sex & -8.542 & 1.805 & -0.427 & $<0.001$ \\
\hline Sum of four skinfolds & -0.362 & 0.064 & -0.598 & $<0.001$ \\
\hline MVPA & 0.050 & 0.087 & 0.056 & 0.570 \\
\hline VPA & 0.143 & 0.110 & 0.123 & 0.210 \\
\hline
\end{tabular}

Multiple regression analysis adjusted for age, sex, sum of four skinfolds, pubertal status, MVPA and VPA. The variables age, sex, sum of four skinfolds and pubertal status were only presented when statistical significant. Sex $1=$ male, $2=$ female. $P<0.05$ indicates statistical significance

MVPA moderate-to-vigorous physical activity ( $\min _{\text {day }}{ }^{-1}$ ), $V P A$ vigorous physical activity $\left(\min ^{-1} \mathrm{day}^{-1}\right), r M S S D$ square root of the mean squared differences of successive normal-to-normal intervals (ms)

Table 3 Descriptive characteristics of physical activity measurements dichotomized according to the daily time spent in moderate-to-vigorous and vigorous physical activity

\begin{tabular}{|c|c|c|c|c|c|c|}
\hline & \multicolumn{3}{|l|}{ Model 1} & \multicolumn{3}{|l|}{ Model 2} \\
\hline & \multicolumn{3}{|c|}{ Moderate-to-vigorous physical activity } & \multicolumn{3}{|c|}{ Vigorous physical activity } \\
\hline & Low $(N=22)$ & $\operatorname{High}(N=23)$ & $P$ value & Low $(N=22)$ & $\operatorname{High}(N=23)$ & $P$ value \\
\hline Female sex $(N(\%))$ & $15(66 \%)$ & $13(57 \%)$ & 0.542 & $15(68 \%)$ & $13(57 \%)$ & 0.542 \\
\hline Accelerometer wear time (days) & $7.0(1.0)$ & $8.0(1.0)$ & 0.718 & $8.0(1.0)$ & $7.0(1.0)$ & 0.124 \\
\hline Total PA (counts $\min ^{-1}$ ) & $361.25(146.8)$ & $410.2(110.1)$ & 0.077 & $328.2(129.1)$ & $431.2(60.2)$ & $<0.001$ \\
\hline Light PA (min day ${ }^{-1}$ ) & $152.1 \pm 28.0$ & $150.8 \pm 35.0$ & 0.886 & $143.4 \pm 31.0$ & $159.1 \pm 30.4$ & 0.094 \\
\hline MVPA (min day ${ }^{-1}$ ) & $24.8 \pm 6.8$ & $41.9 \pm 7.6$ & $<0.001$ & $28.9 \pm 9.4$ & $37.8 \pm 11.1$ & 0.005 \\
\hline VPA (min day $\left.{ }^{-1}\right)$ & $8.1(7.3)$ & $11.2(8.4)$ & 0.080 & $5.4(6.0)$ & $13.2(5.8)$ & $<0.001$ \\
\hline Sedentary activity $\left(\right.$ minday $^{-1}$ ) & $702.9(85.3)$ & $735.8(76.7)$ & 0.266 & $739.9(97.4)$ & $715.5(56.5)$ & 0.401 \\
\hline \multicolumn{7}{|l|}{ Bouts of $\geq 5$ min of MVPA } \\
\hline Total daily bouts $(N)$ & $1.88(1.5)$ & $3.40(2.2)$ & $<0.001$ & $1.90(1.0)$ & $2.40(2.0)$ & 0.062 \\
\hline Average time per bout (min) & $8.0(2.0)$ & $8.5(2.0)$ & $<0.001$ & $7.6(2.0)$ & $7.6(2.0)$ & 0.524 \\
\hline \multicolumn{7}{|l|}{ Bouts of $\geq 5$ min of VPA } \\
\hline Total daily bouts $(N)$ & $0.10(0)$ & $0.30(1.0)$ & 0.524 & $0(0)$ & $0.5(0)$ & $<0.001$ \\
\hline Average time per bout (min) & $5.8(10.0)$ & $6.7(10.0)$ & 0.588 & $0(8.0)$ & $8.4(4.0)$ & 0.012 \\
\hline
\end{tabular}

Data are presented as mean $\pm \mathrm{SD}$ or median (inter-quartile range) or $N(\%) . \dot{V} \mathrm{O}_{2 \text { peak }}$ peak oxygen consumption. Data were analyzed using Student's $t$ test or Mann-Whitney $U$ test or $\chi^{2}$ test. A $P$ value $<0.05$ indicates statistical significance

$M V P A$ moderate-to-vigorous physical activity, $P A$ physical activity, $V P A$ vigorous physical activity

While previous studies with relatively small sample sizes reported positive associations between the two methods (Dhindsa et al. 2008; Nohria et al. 2006), recent data using sex- and age-adjusted and multivariable-adjusted analyses on a large population revealed no associations between PAT and FMD (Hamburg et al. 2011). By direct comparison, inhibition 
Fig. 2 Comparison of reactive hyperemic index, rMSSD, power output and systolic blood pressure between the low versus high MVPA group (model 1) and the low versus high VPA group (model 2). Data are mean \pm SEM. $r M S S D$ square root of the mean squared differences of successive normal-to-normal intervals
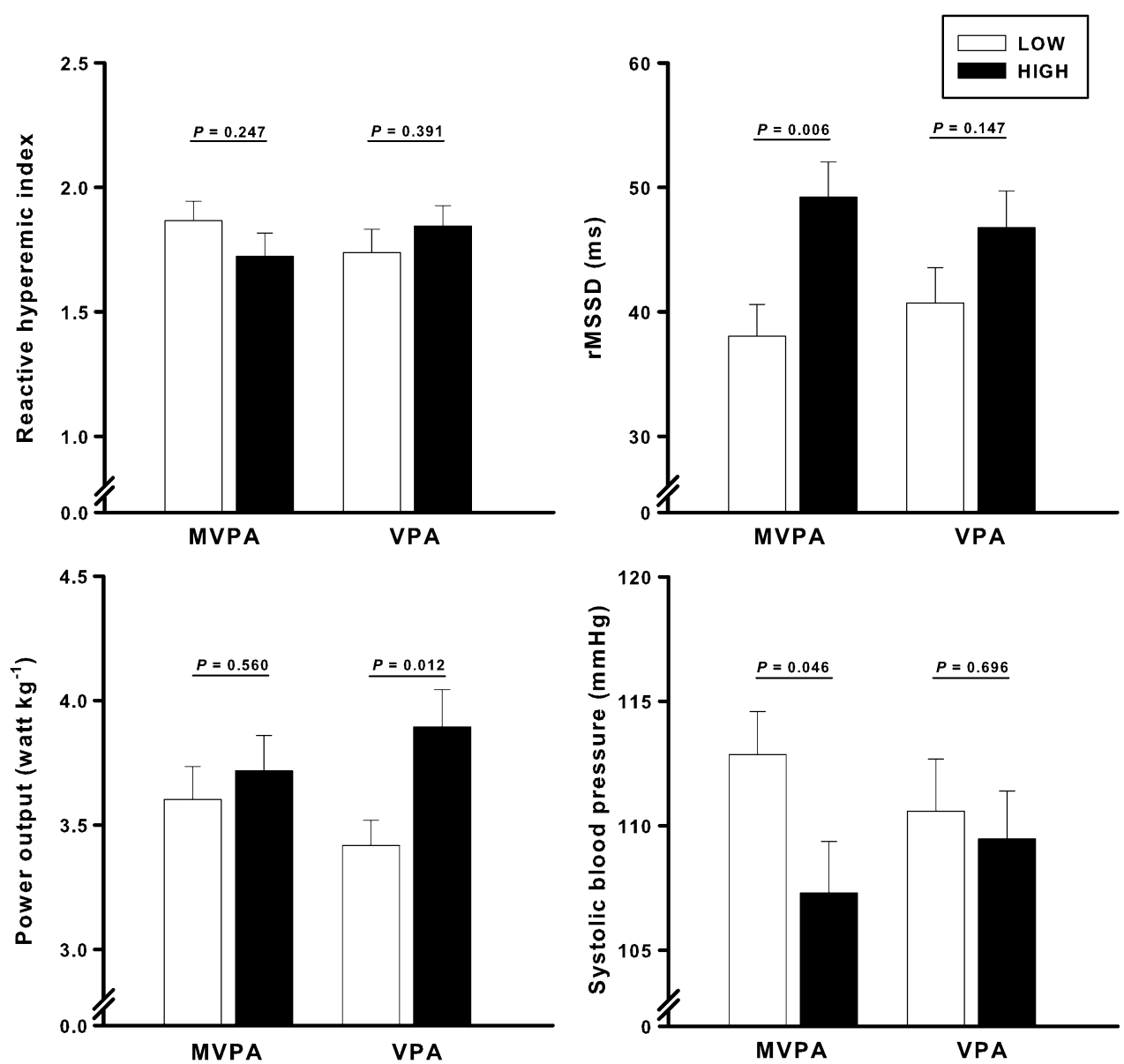

Table 4 24-h ECG Holter monitoring and analysis of time domain heart rate variability parameters

\begin{tabular}{|c|c|c|c|c|c|c|}
\hline & \multicolumn{3}{|l|}{ Model 1} & \multicolumn{3}{|l|}{ Model 2} \\
\hline & \multicolumn{3}{|c|}{ Moderate-to-vigorous physical activity } & \multicolumn{3}{|c|}{ Vigorous physical activity } \\
\hline & Low $(N=22)$ & $\operatorname{High}(N=23)$ & $P$ value & Low $(N=22)$ & $\operatorname{High}(N=23)$ & $P$ value \\
\hline Mean ECG wear time (h) & $23.9 \pm 1.1$ & $23.5 \pm 1.2$ & 0.275 & $23.9 \pm 1.1$ & $23.6 \pm 1.2$ & 0.400 \\
\hline Mean heart rate (bpm) & $82.5 \pm 9.8$ & $77.4 \pm 9.9$ & 0.092 & $80.2 \pm 12.0$ & $79.5 \pm 8.1$ & 0.829 \\
\hline Maximum heart rate (bpm) & $170.7 \pm 18.3$ & $170.2 \pm 17.6$ & 0.921 & $172.0 \pm 15.8$ & $169.9 \pm 20.3$ & 0.382 \\
\hline Minimum heart rate (bpm) & $54.7 \pm 5.4$ & $49.4 \pm 7.3$ & 0.009 & $53.3 \pm 7.5$ & $50.7 \pm 6.2$ & 0.203 \\
\hline rMSSD (ms) & $38.1 \pm 11.7$ & $49.2 \pm 13.6$ & 0.006 & $40.7 \pm 13.1$ & $46.8 \pm 14.1$ & 0.345 \\
\hline SDNN (ms) & $167.0(31)$ & $198.0(76)$ & 0.019 & $167.0(42)$ & $183.0(66)$ & 0.093 \\
\hline SDANN (ms) & $154.0(28)$ & $180.0(69)$ & 0.026 & $156.0(29)$ & $166.0(66)$ & 0.113 \\
\hline HRV triangular index & $49.0(11)$ & $50.0(24)$ & 0.235 & $49.0(20)$ & $50.0(19)$ & 0.580 \\
\hline
\end{tabular}

Data are presented as mean \pm SD or median (inter-quartile range). Data were analyzed using Student's $t$ test or Mann-Whitney $U$ test. A $P$ value $<0.05$ indicates statistical significance

$E C G$ electrocardiograph, $b p m$ beats per minute, $H R V$ heart rate variability, $r M S S D$ square root of the mean squared differences of normal-tonormal intervals, SDNN standard deviation of normal-to-normal intervals, SDANN standard deviation of the average normal-to-normal intervals

of endothelial nitric oxide synthase with intra-arterial infusion of $N^{\mathrm{G}}$-nitro-L-arginine methyl ester (L-NAME) blunted the reactive hyperemic response by only $46 \pm 21 \%$ using PAT (Nohria et al. 2006) while an exclusively nitric oxide-mediated vasodilation of the brachial artery has been observed using FMD during distal wrist occlusion (Doshi et al. 2001).
This underlines the importance of different physiological mechanisms contributing to different vascular responses between measures of micro- versus macrocirculation (Dhindsa et al. 2008), possibly contributing to the lack of relationship in our study sample. Another explanation for the lack of difference in the RHI between our groups could be the 
fact that our adolescents did not engage in a sufficient volume of PA to induce favorable effects on the vascular endothelium at the fingertips. Consistent with our findings, Stone et al. (2009) reported no relationship between objective measures of PA and resting microvascular endothelial function assessed by iontophoresis and laser Doppler perfusion imaging in healthy pre-pubertal boys, suggesting that adaptation in endothelial function to PA levels may be detected in large conduit arteries at an earlier age compared to small resistance vessels. On the other hand, in our study, even small differences in daily MVPA (17 $\mathrm{min}^{\mathrm{day}}{ }^{-1}$ ) were positively related to improved autonomic tone. The high MVPA group exhibited a higher overall sympathetic nervous system activity, higher vagal activity and a lower minimum heart rate. The association of greater volumes of MVPA and higher vagal activity has also been demonstrated with short term recordings of HRV in a cross-sectional study in 304 healthy adolescents (Gutin et al. 2005). In accordance with our data, a 7-week high-intensity intermittent interval training did not translate into improvements in HRV parameters in healthy pre-pubertal children, assuming that moderate rather than vigorous activities positively influence autonomic tone in children and adolescents (Gamelin et al. 2009). While short-term recordings are performed under laboratory conditions, we selected 24-h Holter monitoring to better reflect circadian fluctuation and everyday life activities (Task Force 1996).

We found a 5-6 mmHg difference in systolic blood pressure between the high-volume and low-volume MVPA group (model 1). Even such a small difference may have a clinical impact, as elevated blood pressure values during childhood are known to track into adulthood. In adults, it has been assumed that a reduction of $5 \mathrm{mmHg}$ in the systolic blood pressure distribution is likely to translate into a reduced mortality risk from stroke and coronary heart disease by 14 and $9 \%$, respectively (Whelton et al. 2002). The study of Leary et al. (2008) showed that PA volume rather than PA intensity is predominantly associated with improved blood pressure profiles. Our data suggest that also PA intensity is important, favoring MVPA over VPA. In addition to the beneficial effects observed for MVPA, greater volumes of VPA (model 2) were associated with higher power output values following maximal cardiopulmonary exercise testing. Anderssen et al. (2007), in a crosssectional study of 2,845 school age youths, found low cardiorespiratory fitness strongly associated with clustering of CVD risk factors, independently of age and sex. In adults, reduced exercise capacity is associated with allcause mortality (Myers et al. 2002). In our study, sex and the sum of four skinfolds were strongly influencing factors for power output and $\dot{V} \mathrm{O}_{2 \text { peak }}$. The lack of a relationship between VPA volume and $\dot{V} \mathrm{O}_{2 \text { peak }}$ may partially be explained by genetic predisposition.
The novelty of our study consisted of the simultaneous assessment of a range of surrogate markers of cardiovascular health. Consequently, we were able to differentiate between the specific benefits of MVPA for vagal activity and blood pressure, as well as VPA for fitness in our population of healthy adolescents. Current PA guidelines for school-youth recommend to perform 60 or more minutes of daily MVPA (Strong et al. 2005) and incorporating vigorous intensity aerobic exercises at least three times per week (World Health Organization 2010). In our study, only $16 \%$ were able to reach $\geq 60$ min day ${ }^{-1}$ of MVPA using a threshold of $3,000-5,200$ counts $\min ^{-1}$ (Treuth et al. 2004). However, even a difference of approximately 17 min of daily MVPA resulted in enhanced vagal activity and lower systolic blood pressure between the low versus high activity groups. In addition, higher volumes of daily VPA were associated with an improved exercise capacity.

The present study has certain limitations. First, because of the cross-sectional study design, we cannot establish causal relationships between measures of PA and the selected outcome variables. The lack of difference in PA levels between boys and girls in our study contradicts previous findings (Nader et al. 2008). We believe that this observation is due to selection bias, because we recruited voluntary subjects who were likely to be more active than the non-volunteering peers. Second, we have recently shown that microvascular endothelial function increases with pubertal maturation in healthy children and adolescents (Radtke et al. 2012). Pubertal status may introduce a confounding factor with regard to detecting associations between PA and microvascular endothelial function, as vascular beds in the fingertip in this age group may be differently matured. However, no differences with respect to the mean age and pubertal status existed neither between the groups of model 1 nor model 2. Third, accelerometry measurements were performed during June and October. It has been shown that PA levels, in particular vigorous PA, change with seasonal variation and can potentially impact on microvascular function (Hopkins et al. 2011). In addition, the increased production of estrogen and progesterone during the menstrual cycle in females is known to affect the vasodilatory response of conduit arteries. We did not schedule testing during a particular cycle phase. However, the distribution of girls' menstrual cycle phases (luteal and follicular phase) was well balanced between girls in model 1 and model 2.

\section{Conclusion}

In conclusion, our results support current PA guidelines that both MVPA and VPA are important for cardiovascular 
health. VPA contributed to an improved exercise capacity and MVPA was associated with an enhanced vagal tone and a lower systolic blood pressure. However, in healthy adolescents, higher PA volumes did not translate into an improvement in microvascular endothelial function.

Acknowledgments The authors thank the subjects for volunteering in the study and the staff of the Kantonsschule Olten for providing the testing facilities. The study was financially supported by the Olten Heart Foundation.

Conflict of interest The authors declare that they have no competing interests.

\section{References}

Abbott RA, Harkness MA, Davies PS (2002) Correlation of habitual physical activity levels with flow-mediated dilation of the brachial artery in 5-10 year old children. Atherosclerosis 160:233-239

Andersen LB, Harro M, Sardinha LB, Froberg K, Ekelund U, Brage S, Anderssen SA (2006) Physical activity and clustered cardiovascular risk in children: a cross-sectional study (The European Youth Heart Study). Lancet 368:299-304

Anderssen SA, Cooper AR, Riddoch C, Sardinha LB, Harro M, Brage S, Andersen LB (2007) Low cardiorespiratory fitness is a strong predictor for clustering of cardiovascular disease risk factors in children independent of country, age and sex. Eur J Cardiovasc Prev Rehabil 14:526-531

Berenson GS, Srinivasan SR, Bao W, Newman WP 3rd, Tracy RE, Wattigney WA (1998) Association between multiple cardiovascular risk factors and atherosclerosis in children and young adults. The Bogalusa Heart Study. N Engl J Med 338:1650-1656

Clarkson P, Montgomery HE, Mullen MJ, Donald AE, Powe AJ, Bull T, Jubb M, World M, Deanfield JE (1999) Exercise training enhances endothelial function in young men. J Am Coll Cardiol 33:1379-1385

Dhindsa M, Sommerlad SM, DeVan AE, Barnes JN, Sugawara J, Ley O, Tanaka H (2008) Interrelationships among noninvasive measures of postischemic macro- and microvascular reactivity. J Appl Physiol 105:427-432

Doshi SN, Naka KK, Payne N, Jones CJ, Ashton M, Lewis MJ, Goodfellow J (2001) Flow-mediated dilatation following wrist and upper arm occlusion in humans: the contribution of nitric oxide. Clin Sci (Lond) 101:629-635

Fernandez JR, Redden DT, Pietrobelli A, Allison DB (2004) Waist circumference percentiles in nationally representative samples of African-American, European-American, and Mexican-American children and adolescents. J Pediatr 145:439-444

Gamelin FX, Baquet G, Berthoin S, Thevenet D, Nourry C, Nottin S, Bosquet L (2009) Effect of high intensity intermittent training on heart rate variability in prepubescent children. Eur J Appl Physiol 105:731-738

Gutin B, Howe C, Johnson MH, Humphries MC, Snieder H, Barbeau P (2005) Heart rate variability in adolescents: relations to physical activity, fitness, and adiposity. Med Sci Sports Exerc 37:1856-1863

Hamburg NM, Palmisano J, Larson MG, Sullivan LM, Lehman BT, Vasan RS, Levy D, Mitchell GF, Vita JA, Benjamin EJ (2011) Relation of brachial and digital measures of vascular function in the community: the Framingham heart study. Hypertension $57: 390-396$
Hopkins ND, Stratton G, Tinken TM, McWhannell N, Ridgers ND, Graves LE, George K, Cable NT, Green DJ (2009) Relationships between measures of fitness, physical activity, body composition and vascular function in children. Atherosclerosis 204:244-249

Hopkins ND, Stratton G, Tinken TM, Ridgers ND, Graves LE, McWhannell N, Cable NT, Green DJ (2011) Seasonal reduction in physical activity and flow-mediated dilation in children. Med Sci Sports Exerc 43:232-238

Hopkins N, Stratton G, Ridgers ND, Graves LE, Cable NT, Green DJ (2012) Lack of relationship between sedentary behaviour and vascular function in children. Eur J Appl Physiol 112:617-622

Leary SD, Ness AR, Smith GD, Mattocks C, Deere K, Blair SN, Riddoch C (2008) Physical activity and blood pressure in childhood: findings from a population-based study. Hypertension 51:92-98

Masse LC, Fuemmeler BF, Anderson CB, Matthews CE, Trost SG, Catellier DJ, Treuth M (2005) Accelerometer data reduction: a comparison of four reduction algorithms on select outcome variables. Med Sci Sports Exerc 37:S544-S554

Morris NMU, Udry RJ (1980) Validation of a self-administered instrument to assess stage of adolescent development. J Youth Adoles 9:271-280

Myers J, Prakash M, Froelicher V, Do D, Partington S, Atwood JE (2002) Exercise capacity and mortality among men referred for exercise testing. N Engl J Med 346:793-801

Nader PR, Bradley RH, Houts RM, McRitchie SL, O'Brien M (2008) Moderate-to-vigorous physical activity from ages 9 to 15 years. JAMA 300:295-305

Nagai N, Moritani T (2004) Effect of physical activity on autonomic nervous system function in lean and obese children. Int $\mathrm{J}$ Obes Relat Metab Disord 28:27-33

Nagai N, Hamada T, Kimura T, Moritani T (2004) Moderate physical exercise increases cardiac autonomic nervous system activity in children with low heart rate variability. Childs Nerv Syst 20:209-214

National High Blood Pressure Education Program Working Group on High Blood Pressure in Children and Adolescents (2004) The fourth report on the diagnosis, evaluation, and treatment of high blood pressure in children and adolescents. Pediatrics 114:555-576

Nohria A, Gerhard-Herman M, Creager MA, Hurley S, Mitra D, Ganz $\mathrm{P}$ (2006) Role of nitric oxide in the regulation of digital pulse volume amplitude in humans. J Appl Physiol 101:545-548

Pahkala K, Heinonen OJ, Simell O, Viikari JS, Ronnemaa T, Niinikoski H, Raitakari OT (2011) Association of physical activity with vascular endothelial function and intima-media thickness: a longitudinal study in adolescents. Circulation 124:1956-1963

Radtke T, Khattab K, Eser P, Kriemler S, Saner H, Wilhelm M (2012) Puberty and microvascular function in healthy children and adolescents. J Pediatr. doi:10.1016/j.jpeds.2012.04.033

Rubinshtein R, Kuvin JT, Soffler M, Lennon RJ, Lavi S, Nelson RE, Pumper GM, Lerman LO, Lerman A (2011) Assessment of endothelial function by non-invasive peripheral arterial tonometry predicts late cardiovascular adverse events. Eur Heart J 31:1142-1148

Selamet Tierney ES, Newburger JW, Gauvreau K, Geva J, Coogan E, Colan SD, de Ferranti SD (2009) Endothelial pulse amplitude testing: feasibility and reproducibility in adolescents. J Pediatr 154:901-905

Stone MR, Rowlands AV, Middlebrooke AR, Jawis MN, Eston RG (2009) The pattern of physical activity in relation to health outcomes in boys. Int J Pediatr Obes 4:306-315

Strong WB, Malina RM, Blimkie CJ, Daniels SR, Dishman RK, Gutin B, Hergenroeder AC, Must A, Nixon PA, Pivarnik JM, Rowland T, Trost S, Trudeau F (2005) Evidence based physical activity for school-age youth. J Pediatr 146:732-737 
Task Force of the European Society of Cardiology and the North American Society of Pacing and Electrophysiology (1996) Heart rate variability: standards of measurement, physiological interpretation and clinical use. Circulation 93:1043-1065

Treuth MS, Schmitz K, Catellier DJ, McMurray RG, Murray DM, Almeida MJ, Going S, Norman JE, Pate R (2004) Defining accelerometer thresholds for activity intensities in adolescent girls. Med Sci Sports Exerc 36:1259-1266

Trigona B, Aggoun Y, Maggio A, Martin XE, Marchand LM, Beghetti M, Farpour-Lambert NJ (2010) Preclinical noninvasive markers of atherosclerosis in children and adolescents with type 1 diabetes are influenced by physical activity. J Pediatr 157:533-539

Tsuji H, Venditti FJ Jr, Manders ES, Evans JC, Larson MG, Feldman CL, Levy D (1994) Reduced heart rate variability and mortality risk in an elderly cohort. The Framingham Heart Study. Circulation 90:878-883

Whelton PK, He J, Appel LJ, Cutler JA, Havas S, Kotchen TA, Roccella EJ, Stout R, Vallbona C, Winston MC, Karimbakas J (2002) Primary prevention of hypertension: clinical and public health advisory from The National High Blood Pressure Education Program. JAMA 288:1882-1888

World Health Organization (2010) Global recommendations for physical activity on health 155. http://whqlibdoc.who.int/ publications/2010/9789241599979_eng.pdf

Zulfiqar U, Jurivich DA, Gao W, Singer DH (2010) Relation of high heart rate variability to healthy longevity. Am J Cardiol 105:1181-1185 